\title{
MEASUREMENT AND MODELING OF THE SNOWMELT IN THE ANE RIVER BASIN
}

\author{
Pedro Luiz Borges CHAFFE1, Yosuke YAMASHIKI², Kaoru TAKARA ${ }^{3}$ and Maho \\ IWAKI $^{4}$ \\ ${ }^{1}$ Student Member of JSCE, Graduate student, Dept. of Urban and Environmental Engineering, Kyoto University \\ (Kyoto 615-8540, Japan) Email: pedrochaffe@flood.dpri.kyoto-u.ac.jp \\ 2 Member of JSCE, Dr. Eng., Associate Professor, DPRI, Kyoto University (Uji 611-0011, Japan) \\ 3 Fellow of JSCE, Dr. Eng., Professor, DPRI, Kyoto University (Uji 611-0011, Japan) \\ 4 Non-member, Graduate student, Graduate School of Human and Environmental Studies, Kyoto University (Kyoto \\ 606-8501, Japan)
}

\begin{abstract}
Areas with seasonal snow cover are very susceptible to climate change, the correct estimation of snow distribution is essential for water resources management in such places. The objective of this work was to estimate snow accumulation and melt in the Ane River basin, which is located in the North part of Lake Biwa and has seasonal snow cover. We show how the combination of Satellite products, simple point SWE measurements, point and distributed snowmelt models can be useful for estimating the spatial distribution of SWE. The temperature index model calibrated with the point measurement was used for estimating spatially distributed snow cover and compared with MODIS snow product. This method showed good agreement with observed snow cover, but there still room for improvement.
\end{abstract}

Key Words : Lake Biwa, Ane river, snowmelt, temperature-index, satellite image, MODIS

\section{INTRODUCTION}

Water resources management is dependent on our knowledge of the hydrologic cycle and its state variables. With climate change, this activity could become more challenging due to reduced capability of predicting the future environmental states based on our incomplete knowledge of the past. Several factors could affect the hydrologic cycle in the future, e.g., changes in evaporation due to higher temperatures or changes in precipitation form and temporal and spatial distributions. One specially delicate aspect is the change related with seasonal snow cover where more precipitation is expected to come as rain instead of snow and snowmelt becoming earlier in the spring ${ }^{1)}$ such as the case in Western North America ${ }^{2)}$. In operational hydrology, the skill to forecast future streamflow is also highly dependent on accurate snow estimation ${ }^{3)}$.

Japan is a mountainous country where many areas receive a considerable amount of snow in the winter. Its rivers are highly regulated and much of the dam operation depends on the reliable predictability of hydrological factors, e.g., the amount of snowmelt in the spring. Some of the previous studies evaluated the possible impacts of future climate on water resources in Japan by using output from climate models as input to hydrologic models ${ }^{4), 5}$. These studies indicate a similar trend, peak streamflow in the spring will occur earlier and in some cases water shortage might occur during summer, changes that could influence the adaptation of dam operation rules in the future ${ }^{6), 7)}$.

The North part of the Kinki region in Japan is influenced by the Japan sea climate. Due to its significant snowfall and relatively warm temperatures in the winter, this area is considered very susceptive to climate change. Some of the northern basins in this area drain into the Lake Biwa, which is the largest freshwater body in Japan and it supplies water for more than 14 million people. There are several environmental problems of major concern in the Lake ${ }^{8)}$, e.g. loss of aquatic species; changes in DO; and the influence of different dam operations and snowmelt flood on the Lake water quality. It is important that we can 
properly estimate the snow accumulation and melt in this area in order to assess such water quality and quantity issues in Lake Biwa and how different climate scenarios might affect it.

Snow water equivalent (SWE) and snowmelt are usually modeled either using energy balance models or temperature-index models. The advantage of the former one is that it calculates melt as a residual of the heat balance equation; however, they need more meteorological data as input. The latter uses only air temperature and precipitation data, however, its shortcoming is the dependence on the empirical relationship which is usually site specific and difficult to transfer to different locations ${ }^{9)}$. Both classes of models have been widely used in $\operatorname{Japan}^{10-12)}$. Satellite images combined with snow models for constraining snow simulation and for spatial estimation of SWE is another useful option which is becoming widely used ${ }^{13-17)}$.

Despite the relative density of meteorological stations in Japan, there are very few at higher altitudes so values usually need to be interpolated/ extrapolated. Some stations also count with snow depth measurement but as far as we know, there are not any automatic SWE measurements in this study area. SWE measurements are necessary for validating snowmelt models and for the closure of the water budget. The objective of the present study was to estimate snow accumulation and melt in the Ane River basin. We show how the combination of satellite products with simple point SWE measurements and a distributed snowmelt model can be useful for estimating spatial distribution of SWE.

\section{ANE RIVER BASIN}

The area of the Ane River Basin is about $372 \mathrm{~km}^{2}$ and it is located in the Northeast region of Lake Biwa (Fig. 1). It is the largest streamflow contributing basin to Lake Biwa. There is high snowfall in the winter and snowmelt during spring is a major contribution of total streamflow. The average annual temperature is $14.5^{\circ} \mathrm{C}$ and precipitation around $2000 \mathrm{~mm}$ per year, precipitation in winter can go up to $800 \mathrm{~mm}$ in the north part of the basin. The land-use is composed mainly by forest in the mountain area and by urban areas in the lower land.

\section{METEOROLOGICAL AND SNOW DATA}

In order to perform and validate the snowmelt analysis we collected data from different sources that covers a range of different time and spatial scales: point snow depth and SWE observations; precipitation and temperature data from several automated stations; and satellite images for analyzing spatial extent of snow cover. We used data for the winters 2009-2010 and 2010-2011 in our analysis.

\section{(1) Precipitation and Temperature data}

Based on the proximity to our study area, we collected hourly precipitation data of 5 stations maintained the Japanese Ministry of Land, Infrastructure and Transport (Fig. 1) www1.river.go.jp - and 10 minutes resolution precipitation and temperature data of 10 AMeDAS stations maintained by the Japan Meteorological Agency - www.jma.go.jp. The AMeDAS data was aggregated to 1 hour resolution.

\section{(2) Snow depth and SWE measurements}

We manually measured snow depth and SWE in the winters of 2009-2010 and 2010-2011 at 4 points (Fig. 1). Snow was collected by inserting a PVC pipe and digging a pit to take it out. SWE was estimated dividing the collected snow weight by the cross sectional area of the pipe (Fig. 2). The most reliable data obtained were: at Surumi, Tochinoki and Nakanokawachi for the winter of 2009-2010 and at Yanagase and Nakanokawachi for the winter of 2010-2011. However, due to avalanche and road management, Tochinoki and Nakanokawachi data are only reliable until 11 of February 2010 and 26 of February 2011 respectively which corresponds only to the beginning of the melt season.

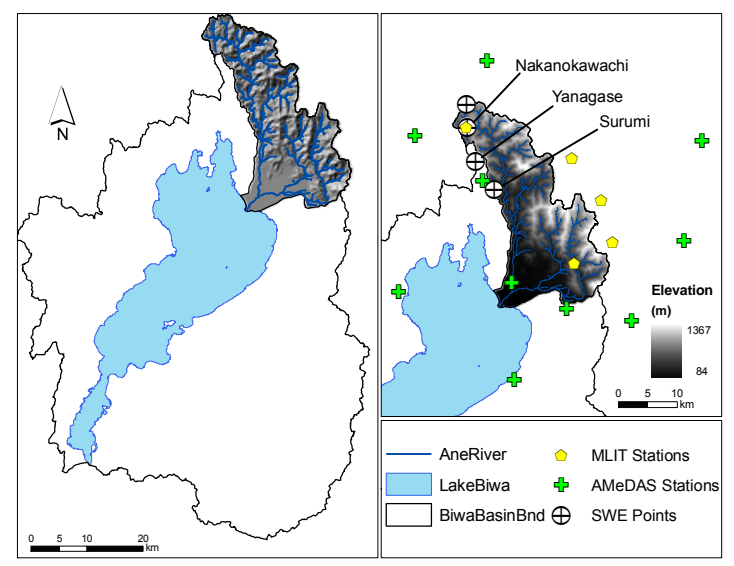

Fig.1 The Ane River basin with the location of the meteorological stations and SWE measurement points.
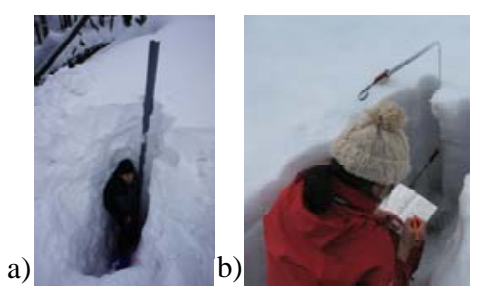

Fig.2 Point measurement of snow depth and SWE. a) At Nakanokawachi. b) At Surumi. 


\section{(3) Data Interpolation}

Interpolation schemes with different degrees of sophistication have been applied for the spatial distribution of meteorological data. Both the more sophisticated ones, e.g. detrended kriging ${ }^{13)}$ that compensates for differences in elevations, and more simple ones, based primarily on lapse rate curves $^{16), 17)}$, have shown satisfactory results. In this case we interpolated both temperature and precipitation data using the natural neighbor interpolation which is a method that computes weights based on a Voronoi tesselation. It fits a smoother function than the simplest linear interpolation. The grid resolution for the interpolation was $250 \mathrm{~m}$ x $250 \mathrm{~m}$.

\section{(4) MODIS snow product}

For satellite image estimation of snow cover in the Ane River basin, we downloaded the product MODIS/Terra Snow Cover 8-Day Global 500m Grid $^{18)}$ of the Moderate Resolution Imaging Spectroradiometer (MODIS) from the National Snow and Ice Data Center (nsidc.org/data). This images contains the maximum snow cover extent over an eight-day compositing period. This data is in HDF-EOS format and comes in a Sinusoidal projection with $500 \mathrm{~m} \times 500 \mathrm{~m}$ resolution, which we projected to UTM, resampled to $250 \mathrm{~m} \times 250 \mathrm{~m}$ resolution and cut to the Ane River basin area.

\section{SNOWMELT MODELING}

Snowmelt was calculated using a temperature-index model at hourly time steps. Firstly the snowmelt model was calibrated and tested for the point measurements. In the next step, the best parameter values were used for the spatially distributed version of the model.

The snowpack accumulation and ablation is calculated using a simple mass balance equation Eq. (1):

$$
\frac{d}{d t} S W E=P_{s}-M
$$

where $S W E$ is the snow water equivalent $(\mathrm{mm}), P_{s}$ is the precipitation in the form of snow $\left(\mathrm{mm} \mathrm{h}^{-1}\right)$, and $M$ the snow melt $\left(\mathrm{mm} \mathrm{h}^{-1}\right)$.

The separation of total precipitation into snow $\left(P_{s}\right)$ and rain was made using an empirical relationship Eq. $(2)^{19)}$. That is the first step for the snow accumulation model.

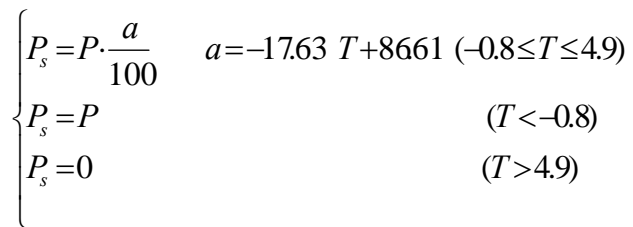

$P$ is the total precipitation $\left(\mathrm{mm} \mathrm{h}^{-1}\right), T$ is the ground air temperature $\left({ }^{\circ} \mathrm{C}\right)$ and $a$ is the probability of occurrence of solid precipitation (\%).

The temperature-index method is calculated according to the commonly used equation ${ }^{9)}$ :

$$
M=\left\{\begin{array}{cc}
\min \left[T F^{*}\left(T-T_{0}\right), S W E\right] & T>T_{0} \\
0 & T \leq T_{0}
\end{array}\right.
$$

where $M$ is the snowmelt $\left(\mathrm{mm} \mathrm{h}^{-1}\right), T F$ is the temperature factor $\left(\mathrm{mm} \mathrm{h}^{-1}{ }^{\circ} \mathrm{C}^{-1}\right), T$ is the mean temperature $\left({ }^{\circ} \mathrm{C}\right)$ for the time step in consideration and $T_{0}$ is the threshold temperature above which melt occurs $\left({ }^{\circ} \mathrm{C}\right)$.

To compensate for precipitation under-catch during the winter, we used a multiplicative parameter to correct the solid precipitation:

$$
P_{s \alpha}=P_{s} * \alpha
$$

where $P_{s \alpha}$ is the corrected solid precipitation and the $\alpha$ is the multiplicative correction factor. There were two parameters calibrated in the snowmelt routine: $T F$ and $\alpha$.

\section{RESULTS AND DISCUSSION}

\section{(1) Point snowmelt modeling}

The model was calibrated using the coefficient of determination $\left(R^{2}\right)$ between the SWE simulated values and the observed ones. We sampled the model parameter space using a Monte Carlo generator with a uniform distribution and 10,000 runs for each point data set (Fig. 3). Based on the literature, the parameter space used initially was $T F=0.01$ to 1.00 and $\alpha=1.0$ to 2.0 . The best $T F$ values were around 0.08 and 0.10 . The model was not much sensitive to $\alpha$ (Fig. 3).

Based on the $R^{2}$ and on later visual inspection, we decided on two parameter sets: $T F=0.08$ and $\alpha=1.5$ (accumulates more snow since it has a lower temperature factor and a higher precipitation correction factor); and $T F=0.10$ and $\alpha=1.3$ (accumulates less snow, $T F$ is higher and $\alpha$ is lower). Fig. 4 shows the model run using $T F=0.10$ and $\alpha=1.3$. The fit for Surumi and Yanagase stations are quite good, however the model underestimates the snow accumulation in Nakanokawachi.
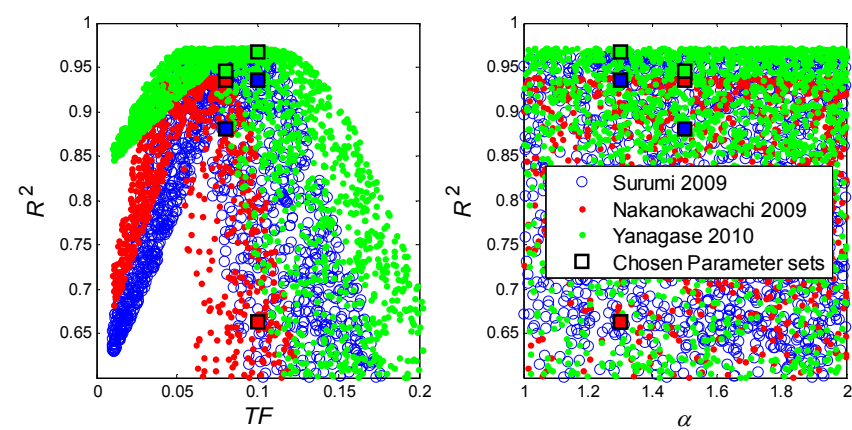

Fig.3 Model sensitivity to the Temperature Factor $(T F)$ and to the precipitation multiplicative correction factor $(\alpha)$. 


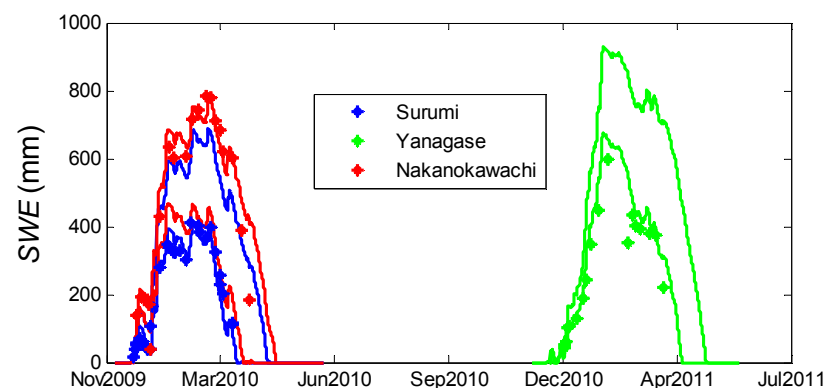

Fig.4 Measured SWE and simulated by both parameter sets. Higher lines correspond to parameters $T F=0.08$ and $\alpha=1.5$ and lower ones correspond to $T F=0.10$ and $\alpha=1$.3.

There are two main reasons for that model behavior in Nakanokawachi: there is very high precipitation in Nakanokawachi, the second one is that Surumi and Yanagase were in a more open space, which facilitates melt. Since there are many areas with high elevation and are covered by forest in Ane River basin and we had only a few SWE measurement points we decided to test those two parameter sets for the distributed snowmelt model.

\section{(2) Distributed snowmelt modeling}

We run the distributed snowmelt model using the two different parameter sets found for the point model. The simulations period for both winters (2009-2010 and 2010-2011) are from $1^{\text {st }}$ December to $30^{\text {th }}$ April. Fig. 5 shows the total snow covered area (SCA) using the MODIS snow product and the distributed model simulations.
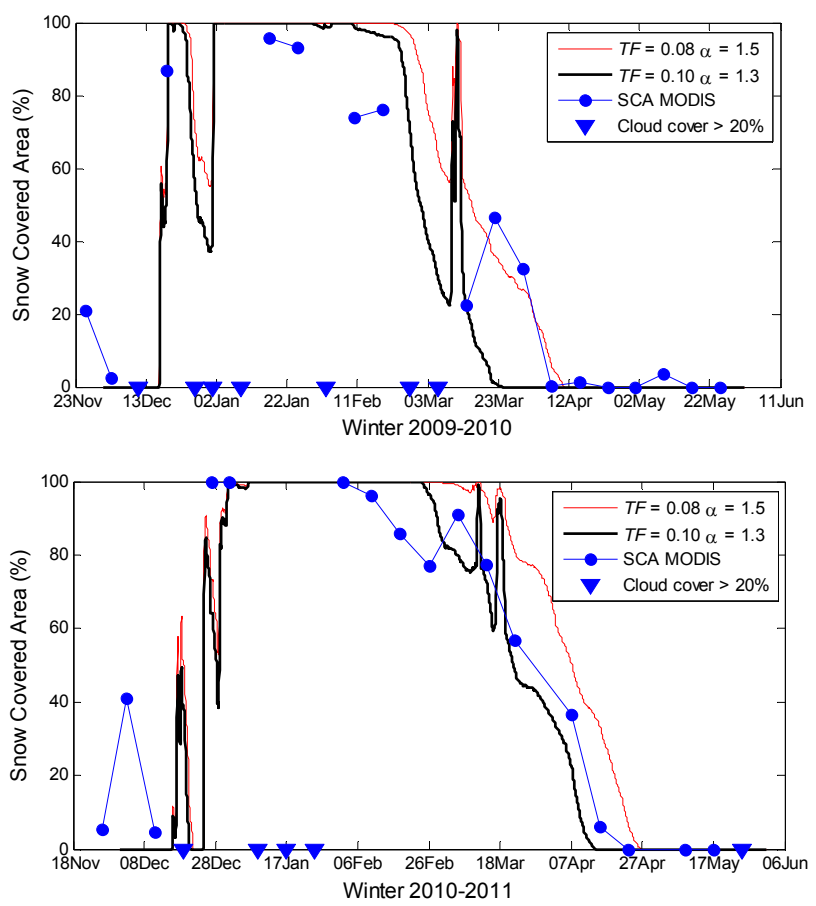

Fig.5 Total snow covered area measured using MODIS snow product, and simulated with the different parameter combinations. Images with cloud cover greater than $20 \%$ were excluded from the analysis.
The days when the cloud cover over the basin was greater than $20 \%$ were excluded from the MODIS analysis as indicated in Fig. 5. The differences between the models are noticed more in the ablation season than in the accumulation one. Although the model that accumulates less snow seems to follow the ablation line of the MODIS product more closely for the second winter, the model that accumulates more snow was more successful in simulating the date of snow disappearance for both winters.

We also examined SCA by elevation bands to check if the model is working for different elevations. Fig. 6 is the result for the winter of 2010-2011, points where the cloud cover for each elevation band were greater than $0.05 \%$ were excluded from the MODIS analysis. In general the models represent well the SCA for each elevation, like the snow disappearance in the end of February and accumulation in the second week of March for the lowest elevations. However, it is noticeable that the SCA of the highest elevation is not so well represented.
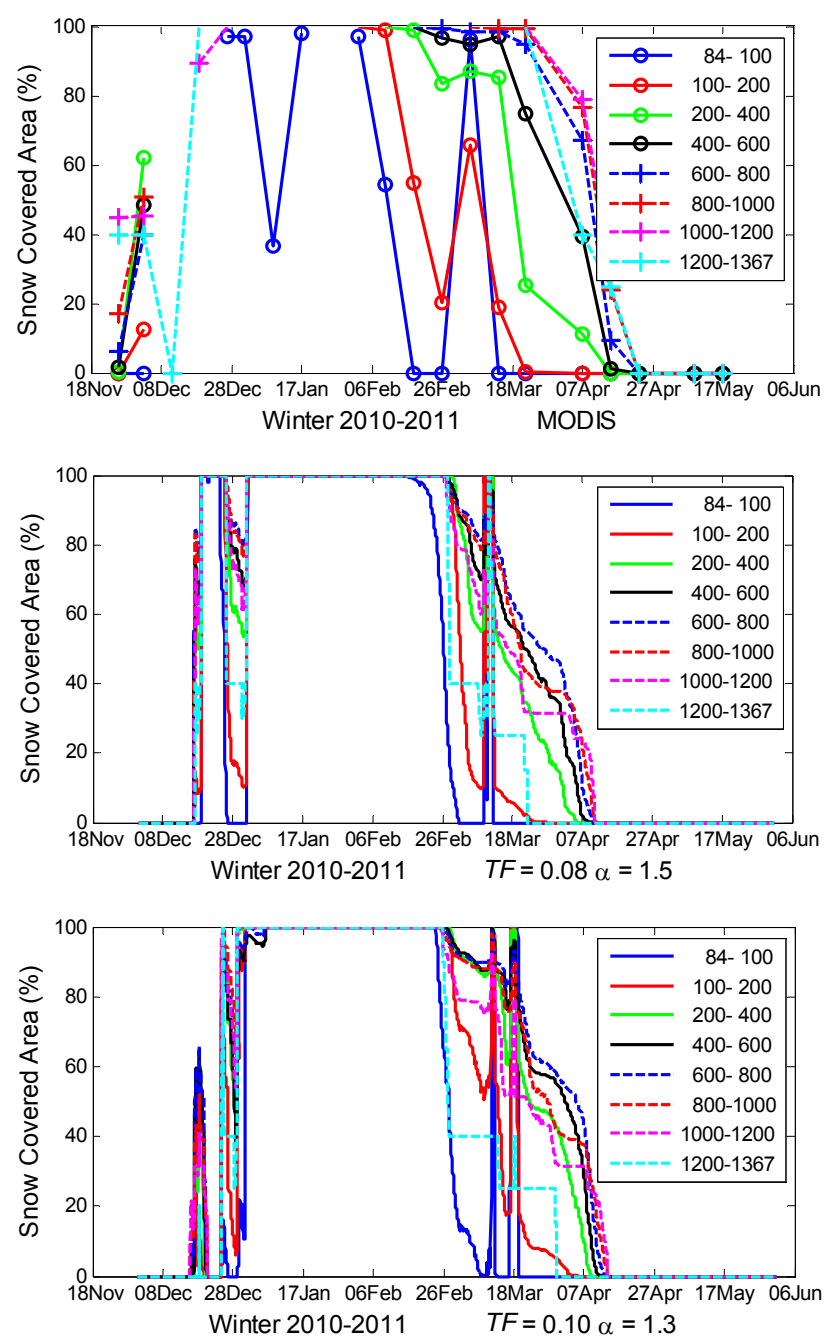

Fig.6 Snow covered area by elevation bands (legend in meters). 
The spatial distribution of snow cover as estimated with MODIS and the spatial distribution of SWE calculated with the models for both winters can be seen in Fig. 7 and Fig. 8, we selected 5 days for comparison for each winter. The simulation in the beginning of the accumulation season is very dependent on the spatial pattern of the input meteorological data. Meteorological stations in the South part are at lower elevation and have less precipitation, which bias the results specially in the lower southern parts in the beginning of the season and in the higher southern part in the end of the
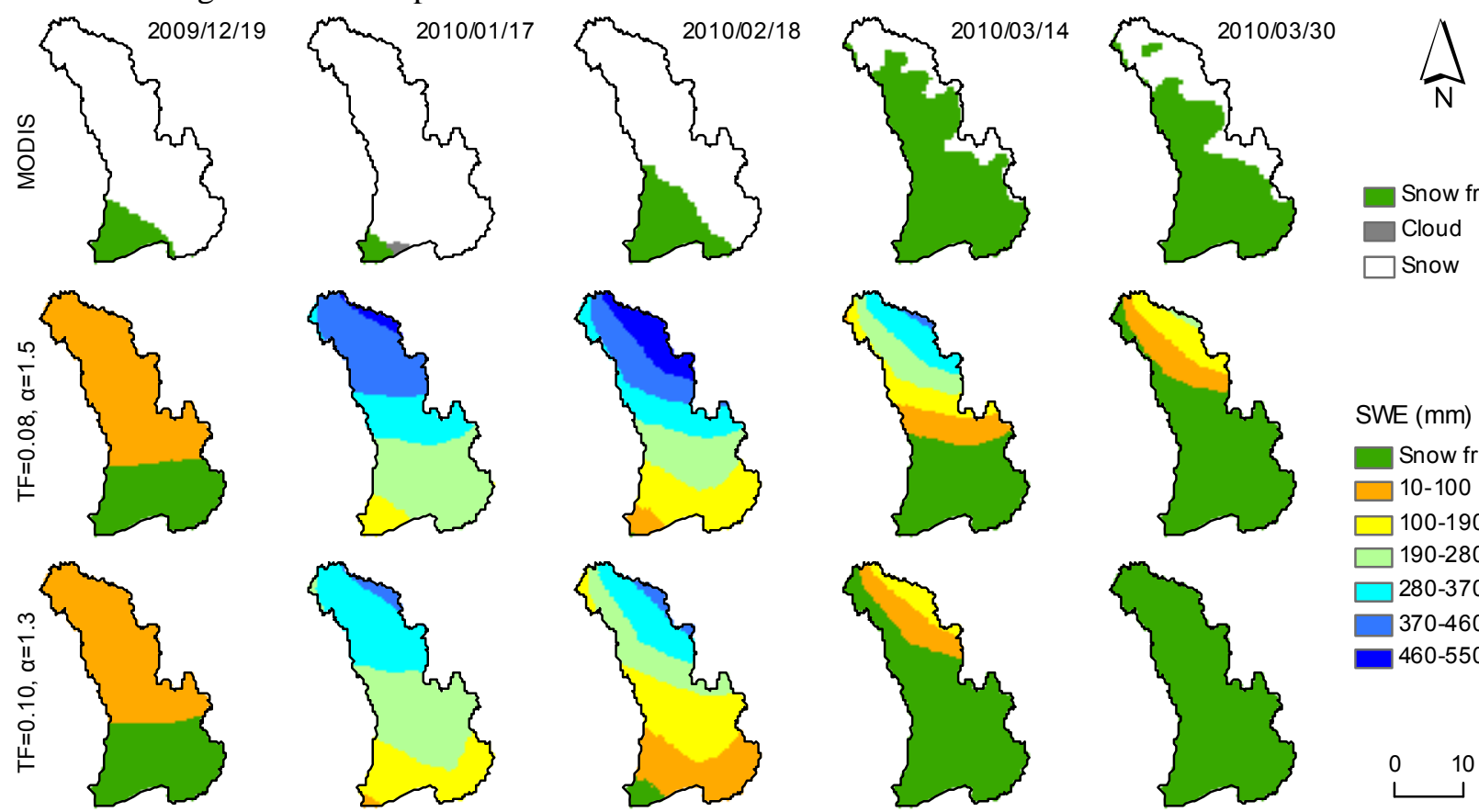

From the simulated spatial patterns in Fig. 7 and 8 it can be seen that in the lower part which is urban and the snow is managed frequently, the snow disappears more quickly than as simulated by the models, indicating the necessity of differentiating between forest and urban area. Despite the fact that the date of snow disappearance is better represented with the model that accumulates more snow, the other model seems to represent better the lower part of the basin in the beginning of the season.
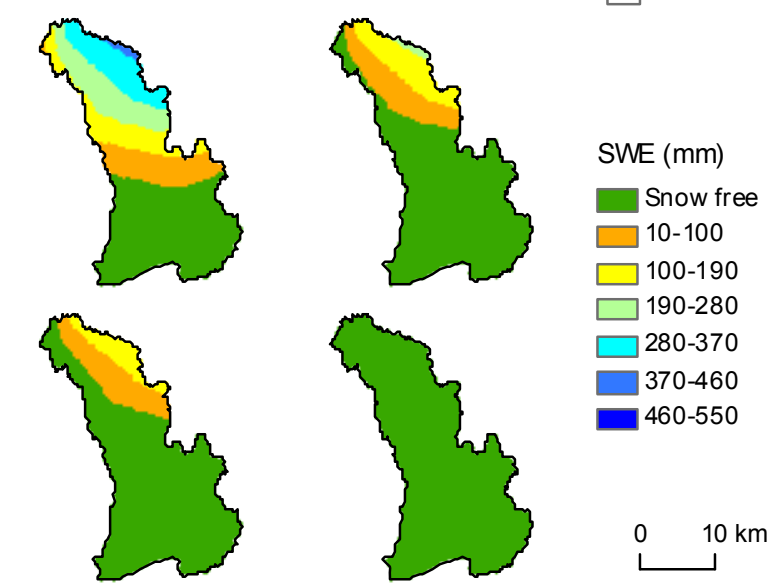

Fig.7 Snow covered area using MODIS (upper panel) and simulated SWE with the chosen parameter sets (two bottom panels) for the Winter 2009-2010.
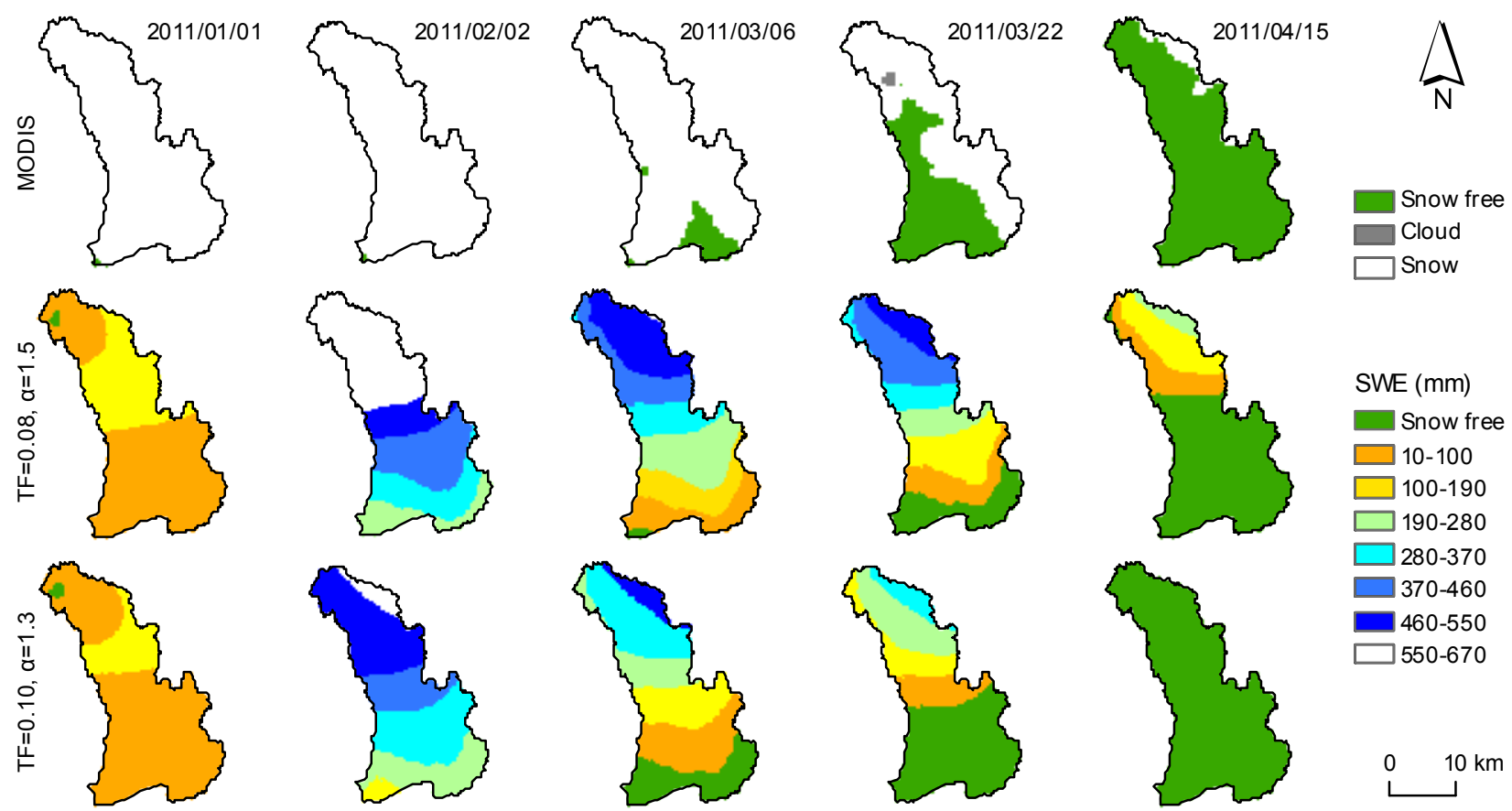

Fig.8 Snow covered area using MODIS (upper panel) and simulated SWE with the chosen parameter sets (two bottom panels) for the Winter 2010-2011. 


\section{CONCLUSIONS}

We combined data from different sources and ranging different spatial and temporal scales with a temperature index snowmelt model in order to estimate distributed snow accumulation and melt in the Ane River basin. Firstly the snowmelt model was calibrated using point measured SWE data. We chose two parameter sets, one with higher snow accumulation and another with lower. This parameters were used in the spatially distributed model. The results were compared with MODIS snow product using SCA for the entire basin and also by elevation bands. The simulated SWE with the higher accumulation model predicted the snow disappearance date better, but the lower one seems to be more reliable in the lower basin part.

The model used uniform parameter values throughout the catchment; for future work, the model parameter should vary with topographic features as well as include uncertainty in the estimation of the spatially distributed snowmelt. There is need for more meteorological and snow data collection in higher places to improve interpolation and also to allow the comparison of simple and sophisticated interpolation methods, since we notice there is a big influence from the meteorological interpolated data on the output.

ACKNOWLEDGMENTS: We would like to thank the GCOE Program "Sustainability/Survivability Science for a Resilient Society Adaptable to Extreme Weather Conditions" (GCOE-ARS) and MEXT for financial support. Help with AMeDAS data collection by Kenichi Tatsumi, field support by Shigeo Fujiki, data collection and discussions with Apip, Joana Nery Giglio, Luo Pingping and Roberto V. da Silva are greatly appreciated.

\section{REFERENCES}

1) Barnett, T. P., Adam, J. C. and Lettenmaier, D. P. Potential impacts of a warming climate on water availability in snow dominated regions, Nature, Vol. 438, pp.303-309, 2005.

2) Mote, P. W., Hamlet, A. F., Clark, M. P. and Lettenmaier, D. P. Declining mountain snowpack in Western North America, Bull. Amer. Meteor. Soc., Vol.86, pp.39-48, 2005.

3) Koster, R. D., Mahanama, S. P. P., Livneh, B., Lettenmaier, D. P. Skill in streamflow forecasts derived from large-scale estimates of soil moisture and snow, Nature Geosci., Vol.3, pp.613-616, 2010.

4) Kim, S., Tachikawa, Y., Nakakita, E. and Takara, K. Hydrologic evaluation on the AGCM20 output using observed river discharge data. Hydrological Research Letters, Vol.4, pp.35-39, 2010.

5) Ma, X., Yoshikane, T., Hara, M., Wakazuki, Y., Takahashi, H. G., Kimura, F. Hydrological response to future climate change in the Agano River basin, Japan, Hydrological
Research Letters, Vol.4, pp 25-29, 2010.

6) Kim, S., Tachikawa, Y., Nakakita, E. and Takara, K. Reconsideration of reservoir operations under climate change: case study with Yagisawa Dam, Japan, Annual Journal of Hydraulic Engineering, Vol.53, pp.115-120, 2009.

7) Kim, S., Tachikawa, Y., Nakakita, E., Yorozu, K. and Shiiba, M. Climate change impact on river flow of the Tone River basin, Japan, Annual Journal of Hydraulic Engineering, Vol.55, pp.85-90, 2011.

8) Kumagai, M., Vincent, W. F., Ishikawa, K. and Aota, Y. Chapter 1, Lessons from Lake Biwa and other Asian lakes: Global and Local perspectives. Freshwater management, Global versus Local perspectives, Springer-Verlag Tokyo, pp. 1-22, 2003.

9) Hock, R. Temperature index melt modeling in mountain areas, Journal of Hydrology, Vol.282, pp.104-115, 2003.

10) S. Suizu, A snowmelt and water equivalent snow model applicable to an extensive area, Journal of the Japanese Society of Snow and Ice, Vol.64, pp.617-630, 2002.

11) Totsuka, T., Kazama, S., Asaoka, Y. and Sawamoto, M. Analysis of the Snow Water Equivalent and the Snowmelt Rate Factor Using the Snow Model and Satellite Information of Snow in the Tohoku District, Japan, J.Japan Soc. Hydrol. \& Water Resources, Vol.17, pp.493-502, 2004.

12) Suzuki, K., Kodama, Y., Nakai, T., Liston, G. E., Yamamoto, K., Ohata, T., Ishii, Y., Sumida, A., Hara, T. and Ohta, T. Impact of land-use changes on snow in a forested region with heavy snowfall in Hokkaido, Japan. Hydrological Sciences Journal, Vol.56, pp.443-467, 2011.

13) Garen, D. C. and Marks, D. Spatially distributed energy balance snowmelt modelling in a mountainous river basin: estimation of meteorological inputs and verification of model results, J. of Hydrology, Vol.315, pp.126-153, 2005.

14) Shamir, E. and Georgakakos, K. P. Distributed accumulation and ablation modeling in the American River basin, Adv. Water Res., Vol.29, pp.558-570, 2006.

15) Kazama, S., Izumi, H., Sarukkalige, P. R., Nasu, T. and Sawamoto. M. Estimating snow distribution over a large area and its application for water resources, Hydrological Processes, Vol.22, pp.2315-2324, 2008.

16) Harshburger, B. J., Humes, K. S., Walden, V. P., Blandford, T. R., Moore, B. C. and Dezzani, R. J. Spatial interpolation of snow water equivalency using surface observations and remotely sensed images of snow-covered area, Hydrol. Processes, Vol.24, pp.1285-1295, 2010.

17) Rice, R., Bales, R. C., Painter, T. H. and Dozier, J. Snow water equivalent along elevation gradients in the Merced and Tuolumne River Basins of the Sierra Nevada, Water Resour. Res., Vol.47, pp.11, 2011.

18) Hall, D. K., Riggs, G. A. and Salomonson, V. V. MODIS/Terra Snow Cover 8-day L3 Global 500m Grid V005. Boulder, Colorado USA: National Snow and Ice Data Center. Digital media, 2006, updated weekly.

19) Iwaki, M., Hida, Y., Ueno, K. and Saijyou, M. Observation of snow water equivalent in the North catchment area of Lake Biwa, Lakes \& Reservoirs: Research and Management, Vol.16, pp.215-221, 2011.

(Received September 30, 2011) 